\title{
Kaposi's varicelliform eruption (eczema herpeticum) in an infant
}

\author{
K
} simplex virus in cases of pre-existent dermatitis. ${ }^{[1]}$ It is most commonly seen between the second to third decades of life, complicating diseases like atopic dermatitis. ${ }^{[2]}$ This case has been presented to generate awareness regarding this easily diagnosed but potentially fatal condition (if left untreated). ${ }^{[3]}$

A 6-month-old boy presented with extensive vesicular rash all over the body along with fever for the past 5 days. He was completely immunized till date and otherwise developmentally normal. The anthropometric parameters were all normal for his age and the systemic examination did not reveal any abnormalities. The patient had an extensive vesicular, umbilicated, asymmetrical rash all over the body, particularly over the face and trunk. There was an associated history suggestive of prior eczematous rash for past 2 months on the face. The patient was being treated for the same with a combination of topical steroids and antibiotics. There was no history of any obvious contact with a case of herpes infection. Laboratory evaluation revealed leucocytosis, a positive C-reactive protein and negative blood culture. There was no family history of atopy. A tzanck smear from vesicles revealed multinucleated giant cells. Vesicular fluid culture could not be done.

A diagnosis of EH was made and the child was treated with oral acyclovir and amox-clavulanic acid. The fever subsided in 2 days and the rash turned pustular and began to heal. The child recovered completely within 7 days and was sent home. He was followed up and was doing well till 3 months after discharge from the hospital.

The true incidence of EH is unknown because of its rarity. Though herpes simplex virus is the most commonly implicated virus, vaccinia virus or coxsackie A16 virus could also be the culprits. ${ }^{[3]}$ Clinical features include eruption of massive crops of vesicles, which rapidly become pustular, then heal without permanent scarring. Fever occurs around 2-3 days after the onset of rash. EH can sometimes arise in nondermatic areas of patients with atopic dermatitis. Disruption of the epidermal barrier of skin, early onset atopic dermatitis and a high level of serum IgE are all possible predisposing factors. A decreased level of cell mediated immunity and defective cytokine secretion have also been implicated. ${ }^{[4]}$ In experimental models, low NK cell activities and increased IL-17 expression increase the susceptibility of atopic patients to eczema vaccinatum. ${ }^{[5]}$ Differential diagnoses include diseases like chicken pox, allergic contact dermatitis and impetigo.

The diagnosis of EH is mainly clinical, although it may be confirmed by tzanck smear, PCR, viral culture, immunofluorescence tests or serology. ${ }^{[6]}$ Potential complications include secondary bacterial infections leading to septicemia, systemic viremia, blepharitis, keratoconjuctivitis (in case of ocular involvement), meningitis and encephalitis. Constitutional symptoms may also be severe in some cases. The drug of choice is acyclovir and treatment is either oral (in mild cases) or intravenous (severe disease). Other antiviral drugs like vidarabine and trifluridine can also be used in unresponsive patients within the pediatric age group.

Sumit Mehndiratta

MBBS, DCH, DNB (Pediatrics), MNAMS

$B$-246 Yojna Vihar

Delhi-110092, India

Email:drsmehndiratta@gmail.com

\section{References}

1 Gupta N, Augustine M, Jayaseelan E. Eczema herpeticum in two elderly patients. Indian J Dermatol Venereol Leprol 2002;68:306-308.

2 Kramer SC, Thomas CJ, Tylery WB, Elston DM. Kaposi's varicelliform eruption: a case report and review of the literature. Cutis 2004;73:115-122.

3 Olson J, Robles DT, Kirby P, Colven R. Kaposi varicelliform eruption (eczema herpeticum). Dermatol Online J 2008; 14:18.

4 Wollenberg A, Zoch C, Wetzel S, Plewig G, Przybilla B. Predisposing factors and clinical features of eczema herpeticum-a retrospective analysis of 100 cases. J Am Acad Dermatol 2003;49:198-205.

5 Kawakami Y, Tomimori Y, Yumoto K, Hasegawa S, Ando T, Tagaya Y, et al. Inhibition of NK cell activity by IL-17 allows vaccinia virus to induce severe skin lesions in a mouse model of eczema vaccinatum. J Exp Med 2009;206:1219-1225.

6 Shenoy MM, Suchitra U. Kaposi's varicelliform eruption. Indian J Dermatol Venereol Leprol 2007;73:65.

doi:10.1007/s12519-010-0228-6 